\title{
A brain death: concepts and confusions among medical experts, legal authorities and general public in Sri Lanka
}

\author{
Ruwanpura P Rohan \\ Consultant Judicial Medical Officer, Teaching Hospital, Karapitiya, Galle.
}

\section{Introduction}

The concept of brain death exists for over hundred years but has been conceptualized only during fifth and sixth decades of the $20^{\text {th }}$ century, especially, after the publication of the landmark paper by the Ad Hoc Committee of the Harvard Medical School ${ }^{1}$. This new scientific definition of brain death ${ }^{2}$ replaced then prevailing socio-biological concept based on cessation of all the functions of a human body, a somatic or biological death, as a legal death. The concept of brain death has now been accepted as a legal definition of death in many parts of the world, of course with great variations in diagnostic criteria ${ }^{3}$. However, it should be realized that a layperson would be reluctant to accept someone with a beating heart, a normal pulse, a normal blood pressure, a normal colour and a normal temperature as dead. Hence, socio-anthropological concept of death, permanent cessation of somatic and social functions of a human body is most applicable to common public sense.

\section{Medico-legal aspects of brain death}

There are many medico-legal issues pertaining to determination of the point of death, or brain death. This include disconnection of the artificial respiration, removal of kidneys and other organs for transplantation, issuing death certificates, maternal rights and rights of live foetus in maternal death, insurance disputes in determining whether the death is a result of an injury or a natural cause, prosecuting with murder charges, arranging final religious and astrological customs. Therefore, it is essential for the medical practitioner to clearly understand medico-legal inferences of this concept.

The brain death may exist in three forms. These are cortical death better known as permanent vegetative state (PVS), brain stem death and whole brain death concept.

\section{Cortical death}

The concept of cortical death ${ }^{4}$ evolved from socio-anthropological definition of death, as a person with cortical death can no longer be recognised as a "social man" 5 . It is true that permanent and irrecoverable dysfunction of the brain will not allow a patient to be back to standard social life, but one should realise that, in many social settings, severely disabled unconscious persons and anencephalic newborns were also being treated as "socially dead" before biological death had occurred. Conversely, a dead body may be treated as alive for some time after physical death due to religious believes of spiritual origin of life. Therefore, permanent vegetative state cannot be equalised to biological death ${ }^{6}$, but may be considered for euthanasia and organ transplantation in case by case basis. The Sri Lankan law does not identify persistent vegetative state as a specific entity and medical professional has no option other than treating him as a deeply comatose patient.

\section{Brain stem death}

The concept of brain stem death is mainly practiced in United Kingdom ${ }^{7}$. The scientific basis of brain stem death relies upon the traditional belief that the cerebral cortex cannot be viable over the dead brain stem. Though the legal requirement for the diagnosis of brain stem death is "irreversible cessation of all functions of the brain stem", it is "accepted" that this requirement has been fulfilled by observing absence of breathing (apnea test) and absence of brain-stem reflexes only ${ }^{8}$. However, there are multiple functions of the brain stem such as control of body temperature, central nervous system control of blood pressure, neurogenic control of heart rate, and hypothalamic-pituitary control of thyroid and adrenal gland influence on maintaining temperature, blood pressure, electrolyte balance, which are not considered 
and may be functioning at the time when patient is called brain dead. The recent advances of neuro-physiological investigations showed the presence of cortical electrical activities over the irreversibly dysfunctioning brain stem. Furthermore, future advancement of computed neurosurgical technologies would facilitate us to replace brain stem functions with everincreasing success ${ }^{9}$, and prolonged survival of a patient with a mechanical brain stem, but otherwise intact cognition, would show the inadequacy of a brain stem definition. The Sri Lankan law does not accept the concept of brain stem death, though many practitioners, being influenced by an English concept moderated by Dr Christopher Pallis ${ }^{10}$, continue to diagnose death by clinical signs of the brain stem dysfunction.

\section{Whole brain concept}

It has been highlighted that only the whole-brain concept, that is the irreversible loss of all functions of the entire brain, is consistent with the death of a man ${ }^{11}$. The concept of whole brain death as definition of death of the individual is accepted in majority of European countries, while the clinical examination and documentation of the clinical signs of brain death are very uniform, there are significant differences in the guidelines for using technical confirmatory tests to corroborate the clinical signs ${ }^{12}$. The definition of death in Sri Lanka is given in the Transplantation Act No. 48 of 1987, which states that irreversible cessation of all functions of the entire brain, including the brain stem, is death ${ }^{13}$. A diagnosis of death shall be determined by standard means of current medical practice, which may include clinical signs of prolonged absence of respiratory and circulatory functions, reflexes, supported by ancillary tests; EEG, Doppler's sonography, carotid angiography, CT scan or any future advancement of brain function tests as appropriate. In this context, our stand on brain death is wide open to accommodate new technical advancements, and in par with modern concepts practiced in many European countries and USA.

\section{Brain death and organ transplantation}

It should be realized that the transplantation owed its development to advances in surgery and immunosuppressive treatment. Brain Death owed its origin to the development of intensive care ${ }^{14}$. According to provisions of the transplantation Act, once brain death is confirmed by physicians who shall be neither involved nor personally interested in the transplantation process, the cadaver may be considered as a potential organ donor. The main problem here is that many potential healthy organ donors are victims of violence and road trauma, where release of the bodies are subjected to an inquest followed by autopsy examination, under the provisions of criminal procedure code. The provisions of the criminal procedure code cannot be overruled by the transplantation Act.

However, there is no legal bar for consented removal of the organs once the corpse is released after the autopsy, as practiced in corneal, knee joint or skin graft transplant. If organ removal has to be done from a beating heart cadaver, who is a victim of violence, a magisterial permission seems to be necessary for the removal of organs and may be obtained by forwarding a " $\mathrm{B}$ " report to the courts through the investigating police officer or a lawyer of the transplantation team. This specific situation is not addressed in the Sri Lankan law. There are no procedures laid down in criminal and transplant laws to overcome such situations in the Sri Lankan low. Therefore, the medical community, admiring immense benefits to the patient by transplantation surgery, could tactically overcome such legal inconsistencies by mutual understanding between the transplant team and the JMO, who may personally witness the organ removal and incorporate an additional report from transplant surgeon stating that organs removed are healthy and free of significant pathological changes contributory to death. The organs removed for transplantation are essentially of healthy nature and argument by some JMOO that they cannot determine the cause of death without that particular organ, may be a lung, liver or a heart, then becomes invalid. 


\section{Furtherance}

It is worth to outline that, all concepts of the brain death are based on irreversibility of functions of the brain ${ }^{15}$ and not on the extent of actual pathological damages to the neural tissues, whereas, the pathophysiological basis of brain death refers to permanent and total cessation of cerebral circulation. Interestingly, many studies conducted on histopathological examination of brains revealed minimal anatomical changes of the cerebral tissues ${ }^{16}$, though they were clinically confirmed as dead brains.

The discovery of the special malleability of foetal brain tissue, and the ability to stimulate neural cell growth and division with neurotrophic chemicals or gene therapy, raises the possibility that patients with extensive brain damage, sufficient to currently be considered dead, at least by higher-brain standards, may be able to return to some degree of function by transplantation of foetal neural tissue ${ }^{17}$.

Another technology that may eventually challenge our death concepts is cryonic suspension, the freezing of heads, or whole bodies, for eventual reanimation. Cryonics believe that future reanimation will be more successful if they could initiate the freezing before somatic death, and certainly before cerebral death. In my opinion, the development of two way neuro-computer prosthesis to replace the damaged brain stems, and possible neural tissue reparation by nanotechnology robotics will outdate all present concepts of brain death, and scientists and the legal authorities, within next century, may be forcing us back to reconsider old socio-biological concept of death!

\section{References}

1. Zuskier LS, Kolano J. Radionuclide studies in the determination of brain death: criteria, concepts, and controversies. Semin Nucl Med. 2008; 38(4): 262-73.

2. Beecher HK(Chairman). A definition of irreversible coma, Report of ad hoc committee of the Harvard Medical School to examine the definition of brain death. JAMA 1968; 205: 337.
3. Wijdicks EF. Brain death worldwide: accepted fact but no global consensus in diagnostic criteria. Neurology. 2002; 58(1): 20-5.

4. Jannet B, Plum F. Persistent vegetative state after brain damage. Lancet 1972; 1: 734.

5. Brody B. Ethical Questions Raised by the Persistent Vegetative State. Hastings Centre Report 1988; 33-7.

6. McMahan J. The Metaphysics of Brain Death. Bioethics 1995; 9: 91-35.

7. Conference of Medical Royal Colleges and their faculties in the United Kingdom. Diagnosis of Brain Death. Brit Med J 1976; 2: 1187.

8. The President's Commission for the Study of Ethical Problems in Medicine and Biomedical and Behavioural Research. Defining Death: A Report on the Medical, Legal and Ethical Issues in the Determination of Death. Washington, DC: US Government Printing Office; 1981.

9. Stuart Y, Bartlett E. Human death and high technology: the failure of whole-brain formulations. Annals of Internal Medicine 1983; 99: 252-8.

10. Pallis C. Brain stem death- the evolution of a concept. The Medicolegal Journal 1987; 55(2): 85-120.

11. Link J, Schaefer M, Lang M. Concepts and diagnosis of brain death. Forensic science international 1994; 69(3): 195-8.

12. Haupt WF, Rudolf J. European brain death codes: a comparison of national guidelines. J Neural. 1999; 246(6): 432-7.

13. Transplantation of human tissues Act, No. 48, Gazette of the Democratic Socialist Republic of Sri Lanka 1987.

14. Machado C, Kerein J, Ferrer Y, Portela L, de la C García M, Manero JM. The concept of brain death did not evolve to benefit organ transplants. J Med Ethics 2007; 33: 197-3

15. Capron AM, Kass L.A statutory definition of the standards for determining human death: an appraisal and a proposal. Univ Penn Law Rev 1972; 121: 87.

16. Wijdicks EFM, Pfeifer EA. Neuropathology of brain death in the modern transplant era. Neurology 2008; 70: $1234-3$.

17. Tuszynski, M. H., and F. H. Gage. 1995. "Bridging grafts and transient nerve growth factor infusions promote long-term central nervous system neuronal rescue and partial functional recovery." Proceedings of the National Academy of Sciences of the United States of America 92: 4621-5. 